\title{
Controle do tombamento de plântulas de beterraba e tomate pelo tratamento de sementes com quitosana
}

\author{
Sérgio Miguel Mazaro(1), Américo Wagner Júnior(1), Idalmir dos Santos ${ }^{(2)}$, Idemir Citadin $^{(2)}$, \\ Jean Carlo Possenti ${ }^{(1)}$ e Alfredo de Gouvêa ${ }^{(1)}$
}

\begin{abstract}
(1)Universidade Tecnológica Federal do Paraná (UTFPR), Campus Dois Vizinhos, Estrada para Boa Esperança, Km 4, CEP 85660-000 Dois Vizinhos, PR. E-mail: sergio@utfpr.edu.br, americowagner@utfpr.edu.br, jpossenti@utfpr.edu.br, alfredo@utfpr.edu.br (2)UTFPR, Campus Pato Branco, Via do Conhecimento, Km 1, Caixa Postal 571, CEP 85501-970 Pato Branco, PR. E-mail: idalmir@utfpr.edu.br, idemir@utfpr.edu.br
\end{abstract}

Resumo - O objetivo deste trabalho foi avaliar o efeito do tratamento de sementes, com o indutor de resistência quitosana, sobre o tombamento de plântulas de beterraba e tomate, e sua relação com alterações bioquímicas e a defesa vegetal. Cada parcela foi representada por 25 sementes. Os tratamentos consistiram da imersão das sementes em quitosana nas concentrações de $0 ; 0,25 ; 0,5 ; 1 ; 2$ e 4\%. Posteriormente, as sementes foram semeadas em bandejas com o substrato infectado com Rhizoctonia sp., e mantidas em casa de vegetação por 14 dias. A quitosana induziu a resistência das plântulas de beterraba e tomate e reduziu a incidência de tombamento. As concentrações de 1,1 e 2,5\% apresentaram maior eficiência na redução do tombamento, para as culturas da beterraba e tomate, respectivamente. $\mathrm{O}$ uso da quitosana induz o aumento na atividade da enzima fenilalanina amônia-liase (FAL) e interfere nas variáveis bioquímicas foliares de proteínas e açúcares totais e redutores.

Termos para indexação: indução de resistência, proteínas relacionadas à patogênese, tombamento de plântulas.

\section{Control of beet and tomato damping-off by seed treatment with chitosan}

\begin{abstract}
The objective of this study was to evaluate the effect of seed treatment using the resistance inductor chitosan to control damping-off in tomato and beet seedlings, and its relationship with plant biochemical alterations and plant protection. Each plot was represented by twenty-five seeds. Treatments consisted of seed immersion in a chitosan suspension at $0,0.25,0.5,1,2$ and $4 \%$ concentrations. Seeds were then sowed in trays with a substrate infected with Rhizoctonia sp. and maintained in greenhouse conditions for 14 days. Chitosan induced seedling resistance and reduced damping-off. The 1.1 and $2.5 \%$ concentrations were more efficient in controling the damping-off for beet and tomato crops respectively. Chitosan increases the phenylalanine ammonialyase (PAL) activity and interferes with the total proteins and total and reduced sugars rates in the leaves.
\end{abstract}

Index terms: systemic acquired resistance, pathogenesis-related proteins, damping-off.

\section{Introdução}

As culturas do tomate e beterraba apresentam alta suscetibilidade a diversas doenças durante seu cultivo, entre as quais o tombamento de plântulas, também chamado de damping-off. Esta doença causa lesões deprimidas nos tecidos vegetais jovens, que provocam o fendilhamento ou constrição do caule e levam ao tombamento da muda.

O tombamento de plântulas é causado principalmente por fungos dos gêneros Rhizoctonia, Pythium, Phytophthora, Colletotrichum, Phoma, Fusarium, Helminthosporium, Cercospora e Botrytis e pelas bactérias dos gêneros Xanthomonas e Pseudomonas (Bedendo, 1995).
Normalmente, medidas de controle preventivas, como tratamento de sementes e uso de fungicidas, são empregadas pelos produtores. No entanto, a crescente preocupação com a qualidade ambiental e com os padrões de produção agrícola, além do aumento da demanda por produtos saudáveis, tem levado à busca por informações sobre práticas de produção favoráveis à conservação da qualidade do meio ambiente (Campanhola \& Bettiol, 2003). Métodos alternativos de controle de doenças vêm destacando-se, por meio do uso de indutores ou eliciadores que induzam a resistência das plantas aos patógenos (Kuhn, 2007; Silva, 2007). 
A indução de resistência pode ser conceituada como mecanismo de defesa - induzido por agentes bióticos ou abióticos - que confere proteção contra amplo espectro de microrganismos (Durrant \& Dong, 2004; Mazaro, 2007). No nível molecular, a indução de resistência é caracterizada pela ativação de ampla gama de genes latentes relacionados aos mecanismos de defesa da planta contra patógenos.

Entre os indutores de resistência que vêm sendo avaliados na agricultura pode-se citar a quitosana, obtida a partir da reação de desacetilação parcial da quitina presente em invertebrados marinhos, insetos, fungos e leveduras (Mathur \& Narang, 1990). A quitosana age ligando-se a receptores presentes na membrana celular das plantas, mimetiza o fenômeno de reconhecimento que ocorre na interação incompatível entre a planta e o patógeno (Labanca, 2002) e pode inibir as proteinases, promover a lignificação (Terry \& Joyce, 2004), alterar o metabolismo das fitoalexinas (Mazaro et al., 2008), induzir a formação de compostos fenólicos (Bautista-Baños etal., 2006), ativar as enzimas quitinases e beta-1,3-glucanases (Zhang \& Quantick, 1998; Rodrigues et al., 2006), fenilalanina amônia-liase (FAL) (Romanazzi et al., 2002; Rodrigues et al., 2006) e peroxidase (Zhang \& Quantick, 1997). AFAL é talvez a enzima mais estudada no metabolismo secundário vegetal, pois está situada em um ponto intermediário entre o metabolismo primário e secundário, e catalisa uma etapa reguladora na formação de muitos mecanismos de defesa vegetal (Taiz \& Zeiger, 2004). A FAL está localizada nos cloroplastos, principalmente nas membranas dos tilacoides, atua na desaminação da L-fenilalanina e forma ácido trans-cinâmico e amônia. $\mathrm{O}$ ácido trans-cinâmico pode ser incorporado em diferentes compostos fenólicos (ácido 4-cumárico, ácido cafeico, ácido ferúlico) presentes na formação de ésteres, cumarinas, flavonoides e ligninas (Cavalcanti et al., 2005).

A indução de resistência com a utilização de quitosana foi demonstrada em diversas culturas como o feijoeiro, em que a quitosana provocou o aumento na atividade de glucanase (Di Piero \& Garda, 2008). Em um trabalho que avaliou o efeito da quitosana na indução de resistência a Fusarium oxysporum f. sp. tracheiphilum, em plantas de caupi, verificou-se a redução da severidade da doença e o aumento da atividade da FAL e beta-1,3-glucanase (Rodrigues et al., 2006). Pereira et al. (2008) obtiveram quitosana do micélio de Trichoderma sp. e de Rhizopus sp. e observaram que ela conferiu capacidade de proteção a plantas de cacaueiro atacadas por Verticillium dahliae. Cavalcanti et al. (2006) avaliaram alguns indutores, entre eles a suspensão de quitosana proveniente de micélio de Crinipellis perniciosa, e obtiveram proteção em plantas de tomateiro atacadas por Xanthomonas campestris pv. vesicatoria. Esses autores observaram, ainda, aumento na atividade de duas proteínas - quitinase e beta-1,3-glucanase - relacionadas à patogênese em folhas de plantas de tomateiro.

Por mais que se conheçam os efeitos indutores de quitosana, não foram encontrados trabalhos sobre o controle de tombamento em plântulas de beterraba e tomate. Assim, são necessárias pesquisas que contribuam com informações relacionadas ao uso da quitosana para essas culturas.

O objetivo deste trabalho foi avaliar a quitosana como indutor de resistência, em tratamento de sementes de tomate e beterraba para o controle do tombamento de plântulas, e relacionar a quitosana com alterações nas características agronômicas e bioquímicas do tecido vegetal.

\section{Material e Métodos}

Os experimentos foram desenvolvidos na área experimental de olericultura da Universidade Tecnológica Federal do Paraná, Campus Dois Vizinhos, e as análises laboratoriais foram realizadas no Laboratório de Bioquímica e Fitossanidade da mesma Instituição, em 2008.

Os tratamentos aplicados envolveram concentrações de quitosana $(0,25 ; 0,5 ; 1 ; 2$ e $4 \%)$ e a testemunha (água destilada). A quitosana foi dissolvida em ácido acético a 1\% e diluída com água destilada para obtenção das concentrações a serem testadas. As sementes foram imersas na solução de quitosana por $5 \mathrm{~s}$ e semeadas em bandejas com o substrato agrícola Plantmax Fibra Hortaliças (Eucatex, São Paulo, SP), que foi esterilizado em autoclave por 1 hora a $120^{\circ} \mathrm{C}$, e então infectado com Rhizoctonia sp.

Os inóculos de Rhizoctonia foram preparados a partir de isolados obtidos em lavouras de tomate e beterraba, de onde se obtiveram culturas puras em placas de Petri, com meio BDA. As culturas foram mantidas em estufa incubadora tipo BOD a $23 \pm 2^{\circ} \mathrm{C}$, com fotoperíodo de 12 horas. Para inoculação no 
substrato, discos da cultura pura foram colocados em sementes de sorgo autoclavadas, mantidas a $23 \pm 2^{\circ} \mathrm{C}$, com fotoperíodo de 12 horas. As sementes de sorgo contaminadas com Rhizoctonia foram colocadas no substrato esterilizado, na proporção de $20 \mathrm{~g} \mathrm{~kg}^{-1}$ de substrato. Após 24 horas, foram feitas as semeaduras, manualmente, tendo-se colocado uma semente por célula nas bandejas de cultivo. Foi utilizado o delineamento experimental inteiramente casualizado, com seis tratamentos e quatro repetições. A unidade experimental foi composta por 25 sementes, com bandeja contendo quatro unidades experimentais cada uma.

As bandejas foram mantidas em casa de vegetação à temperatura média de $25 \pm 2^{\circ} \mathrm{C}$. As avaliações foram realizadas após 14 dias, tendo-se determinado: a incidência de tombamento após a emergência (percentagem de plantas tombadas); a massa de matéria fresca; o comprimento da radícula e da parte aérea; e as análises bioquímicas (proteínas e açúcares totais e redutores, atividade da enzima FAL).

Para as análises bioquímicas, foi coletada uma amostra de plântulas de aproximadamente $5 \mathrm{~g}$ de todos os tratamentos e repetições de onde foi obtido o material vegetal. Nessas análises foram determinados: proteínas, açúcares totais e redutores, bem como a atividade da FAL. Imediatamente após as coletas, as amostras foram congeladas, em nitrogênio líquido e armazenadas em freezer a $-20^{\circ} \mathrm{C}$, até as avaliações.

Para a dosagem de proteínas, foi empregado o teste de Bradford (1976). As concentrações de açúcares solúveis totais foram determinadas pelo método fenol-sulfúrico descrito por Dubois et al. (1956). Açúcares redutores foram determinados pelo método do dinitrosalicilato (DNS) (Miller, 1959). A determinação da atividade da fenilalanina amonia-liase foi realizada por quantificação colorimétrica do ácido trans-cinâmico, liberado do substrato fenilalanina, conforme Kuhn (2007).

Os resultados obtidos foram submetidos à avaliação de homogeneidade, pelo teste de Bartlett, a 5\% de probabilidade. A análise de variância e a comparação de médias foram feitas pelo teste de Tukey, a 5\% de probabilidade, e as análises de regressão foram feitas pelo Sanest (Zonta \& Machado, 1984).

\section{Resultados e Discussão}

$\mathrm{Na}$ beterraba, concentrações de quitosana acima de 0,5\% aumentaram o desenvolvimento das plântulas, com ganho de massa de matéria fresca (Figura $1 \mathrm{~A}$ ), e induziram resistência com a consequente diminuição do tombamento (Figura 2 A). O maior efeito de indução de resistência, entre as concentrações avaliadas, foi obtido com $1,1 \%$ de quitosana, calculado por meio do ponto mínimo, com tombamento de 36,49\% (Figura 2 A). O ponto máximo foi obtido com $3,25 \%$ de quitosana, tendo-se $68,62 \%$ de tombamento. Observou-se que o efeito indutor da quitosana em beterraba pode ser restrito a determinada faixa de concentração, uma vez
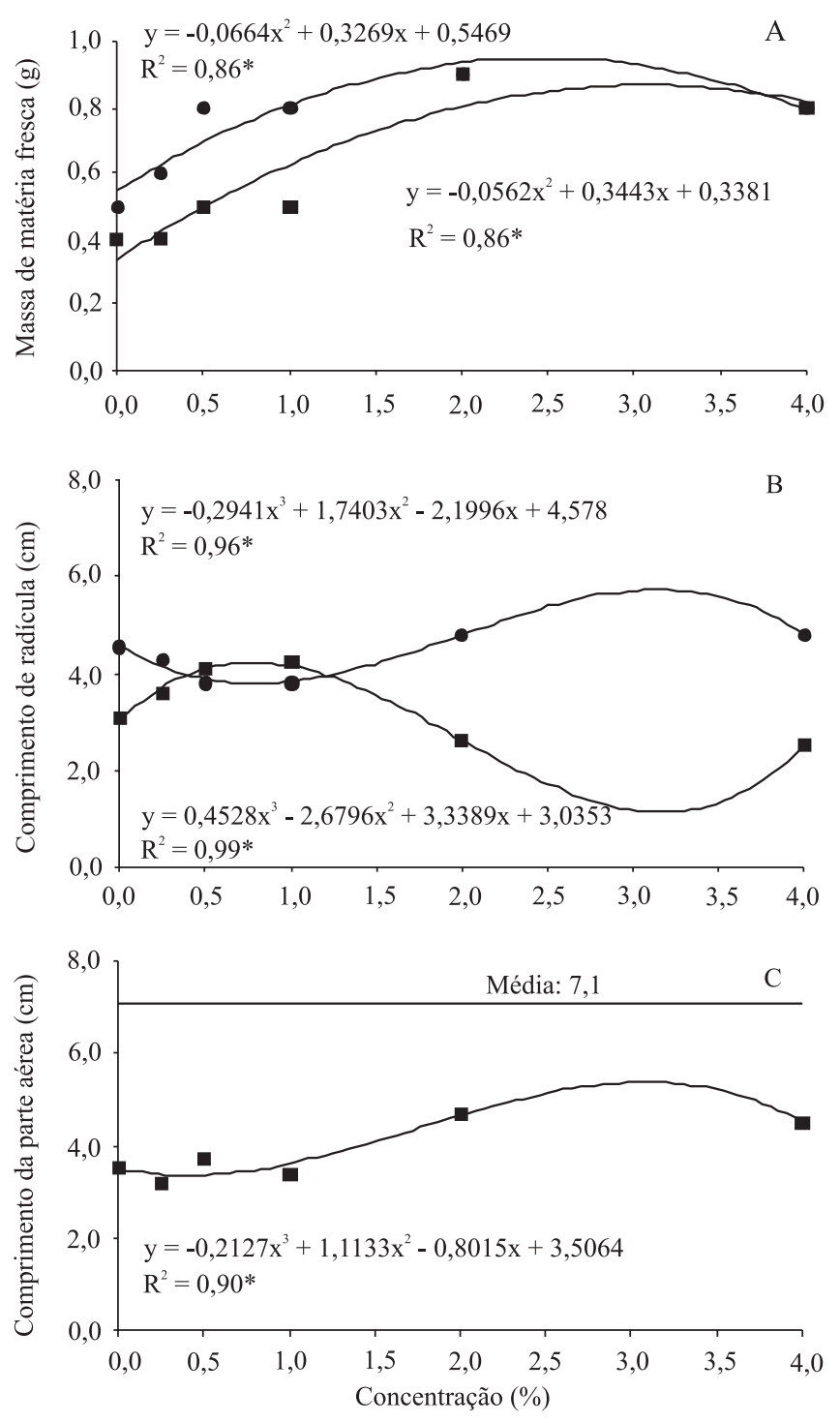

Beterraba $\square$ Tomate

Figura 1. Massa de matéria fresca (A), comprimento de radícula (B) e da parte aérea de plântulas (C) de beterraba e de tomate não tratadas e tratadas com quitosana em cinco concentrações. *Significativo a $5 \%$ de probabilidade. 
que em concentrações maiores o efeito não foi obtido (Figura $2 \mathrm{~A}$ ).

As maiores médias para o comprimento da radícula das plântulas de beterraba foram obtidas nas concentrações entre 2 e 4\% (Figura 1 B). Ao comparar esses resultados com os da Figura 2 A, observou-se que houve menor desenvolvimento de raízes nas concentrações nas quais a incidência de tombamento foi menor. $\mathrm{O}$ mesmo foi observado para o tomateiro (Figuras 1 B e 2 B). Possivelmente, o uso da quitosana fez com que rotas metabólicas e reservas destinadas ao desenvolvimento radicular fossem empregadas na defesa contra o tombamento. Esses efeitos podem ocorrer quando se faz uso de indutores de resistência, em consequência de desvios de rotas metabólicas para síntese de compostos de defesa (Heil \& Bostock, 2002). Em plantas de feijoeiro, o uso do indutor de resistência acibenzolar-s-metil (ASM) alterou o metabolismo
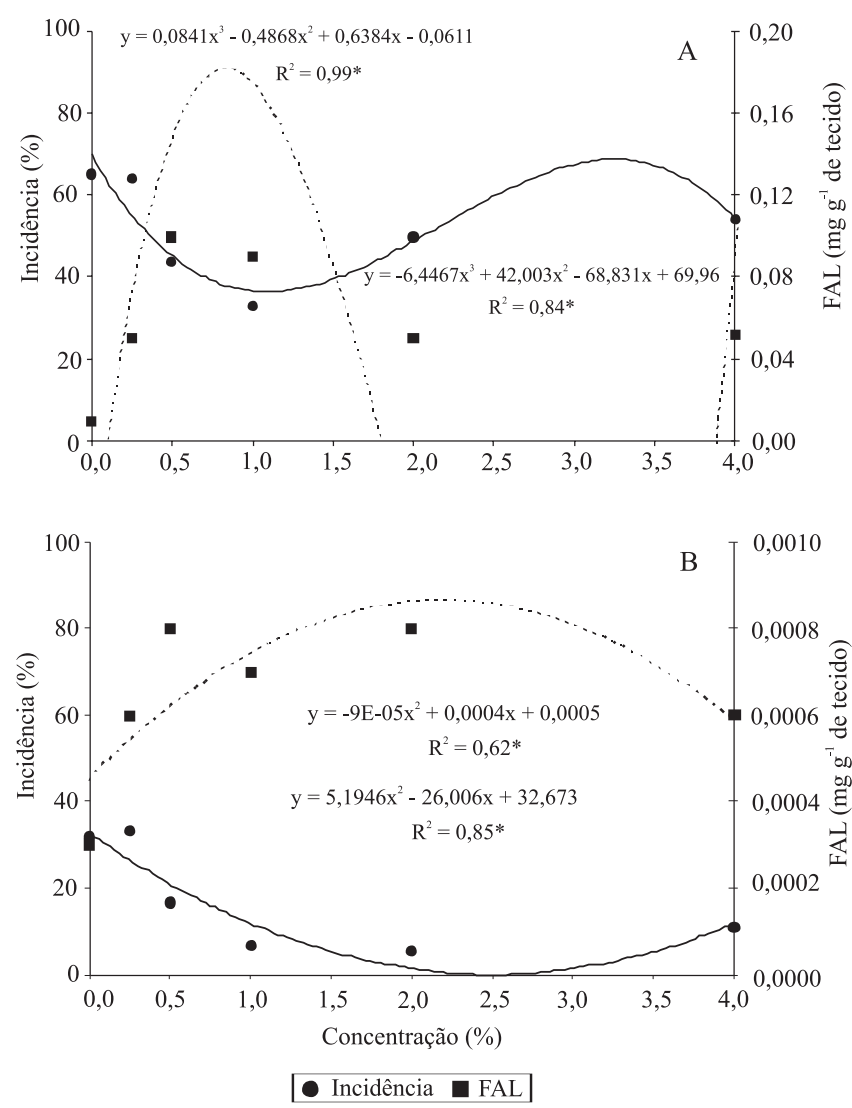

Figura 2. Incidência de tombamento de plântulas de beterraba (A) e tomate (B) e atividade da fenilalanina amônialiase (FAL), em função das concentrações de quitosana aplicadas no tratamento de sementes. *Significativo a $5 \%$ de probabilidade. da planta, redirecionando os fotoassimilados para mecanismos de defesa, com redução da produtividade (Kuhn, 2007). A diminuição do rendimento em cebolas também foi observada, quando se avaliou o efeito da aplicação foliar do polissacarídeo ulvana, obtido da alga Ulva sp., na indução de resistência para o controle do míldio e da podridão-de-escamas (Wordell Filho et al., 2007).

O comprimento da parte aérea das plântulas de beterraba não apresenta diferenças significativas entre as concentrações de quitosana utilizadas, com média de 7,1 cm (Figura $1 \mathrm{C}$ ).

No tomateiro, houve maior ganho de massa de matéria fresca e maior desenvolvimento da parte aérea quando se utilizou a quitosana, em concentrações acima de $2 \%$ (Figura 1 A e C). Na concentração de 2,5\% de quitosana houve menor incidência de tombamento $(0,128 \%)$ (Figura $2 \mathrm{~B})$.

Estes resultados mostraram o potencial de utilização de quitosana como indutor de resistência no controle de tombamento de plântulas de beterraba e tomate. Resultados similares com uso de quitosana foram observados em plantas de pepino com a indução de respostas de defesa, inclusive com formação de barreiras estruturais nos tecidos das raízes e o estímulo das hidrolases, contra a podridão-das-raízes causada por Pythium aphanidermatum (El Ghaouth et al., 1994).

Para beterraba e tomate, o uso do indutor interferiu nas variáveis bioquímicas foliares de açúcares totais, acúcares redutores e proteínas totais (Figura 3 A, B, C), e na atividade da enzima fenilalanina amônia-liase (FAL) (Figura $2 \mathrm{~A}$ e B).

Para beterraba, o maior teor proteico foi obtido em concentrações acima de 1\% (Figura $3 \mathrm{C}$ ). No tomateiro, o maior teor foi observado na testemunha $\left(19,8 \mathrm{mg} \mathrm{g}^{-1} \mathrm{de}\right.$ tecido), no entanto, sem diferença estatística com a média dos tratamentos, com teor proteico de $17,65 \mathrm{mg} \mathrm{g}^{-1} \mathrm{de}$ tecido.

Em beterraba, os maiores teores de açúcares totais foram obtidos nas concentrações de 0,2 e $4 \%$, e para o tomateiro, somente a testemunha foi maior para essa variável. As maiores médias para açúcares redutores foram observadas nas concentrações a partir de $0,5 \%$ em beterraba (Figura 3 B), o que não foi verificado para o tomateiro, que apresentou média de $0,009 \mathrm{mg} \mathrm{g}^{-1} \mathrm{de}$ tecido (Figura $3 \mathrm{~B}$ ). 
Essas alterações nas variáveis bioquímicas de macromoléculas - como nas proteínas totais, açúcares redutores (glicose, manose e frutose) e açúcares totais (redutores e sacarose) - podem estar relacionadas ao aumento da atividade metabólica das plântulas, pois os ciclos metabólicos estão integrados. Um processo de indução de compostos do metabolismo secundário pode afetar o metabolismo primário do carbono como
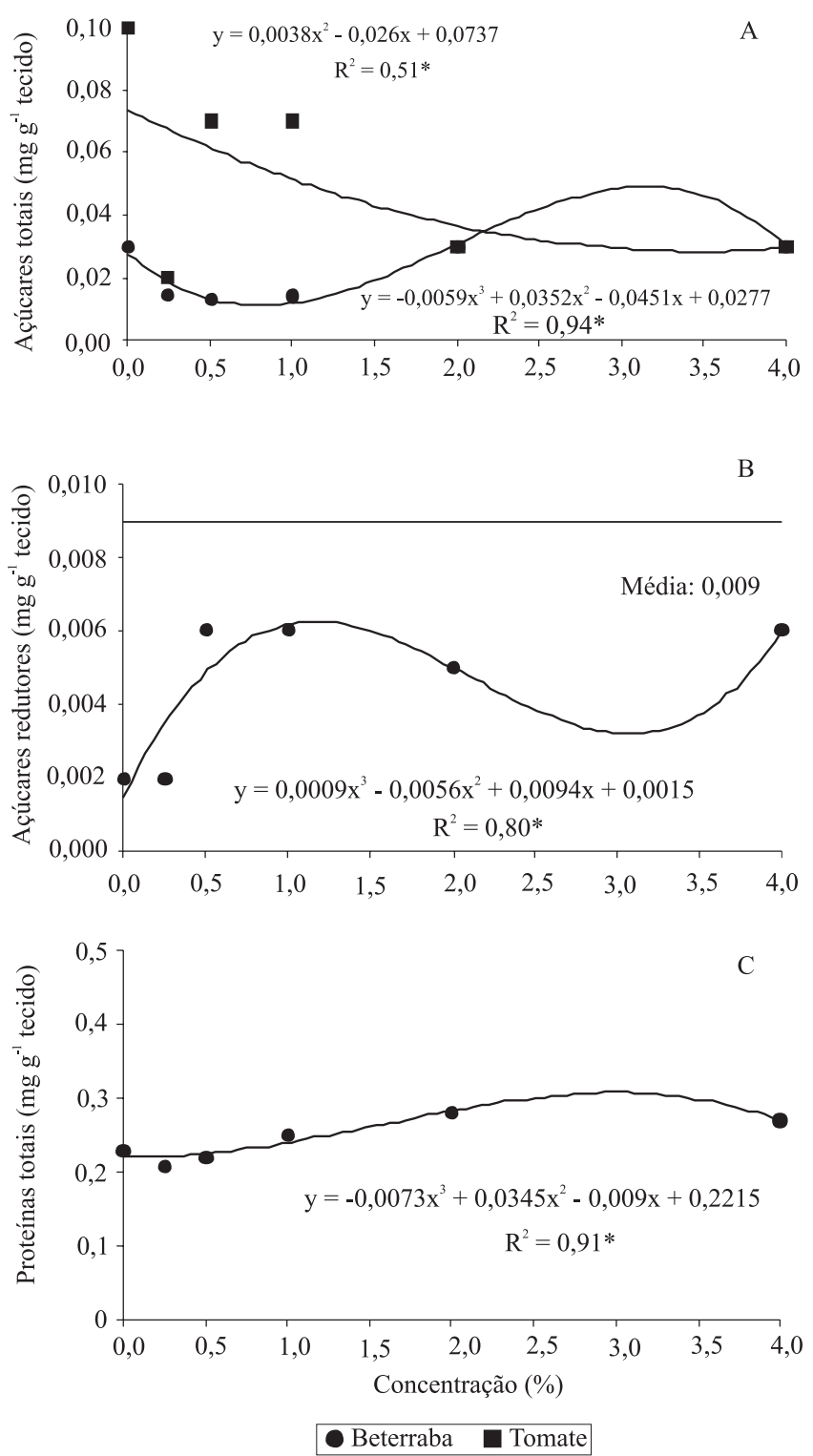

Figura 3. Concentração de açúcares totais (A), açúcares redutores $(\mathrm{B})$ e proteínas totais $(\mathrm{C})$, presentes nos extratos de plântulas de beterraba e tomate não tratadas e tratadas com quitosana em cinco concentrações. * Significativo a 5\% de probabilidade. a glicólise, pentose fosfato ou ciclo do ácido cítrico (Mazaro 2007).

Kuhn (2007) trabalhou com o indutor de resistência acibenzolar-S-metil (ASM) em feijoeiro e obteve alteração nos níveis de proteínas totais e açúcares redutores, tendo indicado que a elevação dos níveis de proteínas está relacionado à síntese de proteínas associada à patogênese, além de outras proteínas de defesa vegetal. Segundo Kuhn (2007), a elevação dos níveis de açúcares redutores pode ser evidência da inversão no processo de armazenamento, visto que, para a planta manter um nível respiratório mais elevado, há necessidade de açúcares simples disponíveis.

A atividade da enzima FAL foi estimulada com a aplicação de quitosana, independentemente da concentração utilizada, uma vez que, em ambas as culturas, houve diferenças nas concentrações de FAL em comparação às da testemunha (Figura 2 A e B). Os maiores valores obtidos para FAL ocorreram com as concentrações de 0,5 e $1 \%$ e, 0,25 a $4 \%$ de quitosana para beterraba e tomate, respectivamente. A melhor eficiência técnica, calculada por meio da regressão, ocorreu nas concentrações de 1,10 e 2,50\%, para beterraba e tomate, respectivamente (Figura 2 A e B).

$\mathrm{O}$ aumento da atividade da FAL e a redução da incidência do tombamento de plântulas (Figura $2 \mathrm{~A} \mathrm{e} \mathrm{B}$ ) indicam que a quitosana atua via rota dos fenilpropanoides para formação de compostos de defesa. A produção de moléculas de defesa vegetal - antocianinas, flavonoides, taninos condensados e isoflavonoides - é desencadeada por enzimas da rota dos fenilpropanoides, ativadas principalmente pela fenilalanina amônia-liase, a primeira e mais importante enzima envolvida nesta rota (Lemos, 2006). Outros autores, como Danner et al. (2008), sugerem essa relação, pois observaram aumento dos níveis de fenóis totais e da atividade da FAL, pelo uso dos eliciadores Messenger, Pro Acte e ASM; sugerem, ainda, que os eliciadores ativaram a rota dos fenilpropanoides, ou seja, potencializaram os mecanismos envolvidos na síntese de compostos fenólicos, como as fitoalexinas e, principalmente, a lignina, que confere à parede celular maior resistência aos patógenos.

Trabalhos de pesquisa devem dar continuidade a essas respostas obtidas quanto às culturas de beterraba e tomate, pelo uso do indutor quitosana, em razão dos diversos mecanismos possíveis de atuação nas plantas e nos patógenos, que devem ser complementadas com 
informações sobre condições ambientais, nutricionais, cultivares, efeitos sobre patógenos, pressão de inóculo, entre outros fatores relacionados à resposta da planta. Os resultados observados neste trabalho mostram que a quitosana tem efeito na indução da enzima de defesa vegetal fenilalanina amônia-liase e tem potencial de utilização no controle de tombamento de plântulas de beterraba e tomate.

\section{Conclusões}

1. O tratamento de sementes de beterraba e de tomate com o indutor quitosana induz a resistência de plântulas e reduz a incidência do tombamento.

2. $\mathrm{O}$ uso do indutor interfere nas variáveis bioquímicas foliares de proteínas totais, açúcares totais e açúcares redutores e induz o aumento da atividade da enzima fenilalanina amônia-liase nas plântulas de beterraba e tomate.

\section{Referências}

BAUTISTA-BAÑOS， S.; HERNÁNDEZ-LAUZARDO, A.N.; VELÁZQUES-DEL VALLE, M.G.; HERNÁNDEZ-LÓPEZ, M.; BARKA, E.A.; BOSQUEZ-MOLINA, E.; WILSON, C.L. Chitosan as a potential natural compound to control pre and postharvest diseases of horticultural commodities. Crop Protection, v.25, p.108-118, 2006.

BEDENDO, I.P. Damping-off. In: BERGAMIN FILHO, A.; KIMATI, H.; AMORIM, L. (Ed.). Manual de fitopatologia: princípios e conceitos. 3.ed. São Paulo: Agronômica Ceres, 1995. v.1, p.820-828.

BRADFORD, M.M. A rapid and sensitive method for the quantification of microgram quantities of protein utilizing the principle of protein-dye binding. Analytical Biochemistry, v.72, p.248-254, 1976.

CAMPANHOLA, C.; BETTIOL, W. Panorama sobre o uso de agrotóxicos no Brasil. In: CAMPANHOLA, C.; BETTIOL, W. (Ed.). Métodos alternativos de controle fitossanitário. Jaguariúna: Embrapa Meio Ambiente, 2003. p.13-51.

CAVALCANTI, F.R.; RESENDE, M.L.V. de; PEREIRA, R.B.; COSTA, J. de C. do B.; CARVALHO, C.P. da S. Atividades de quitinase e beta-1,3-glucanase após eliciação das defesas do tomateiro contra a mancha-bacteriana. Pesquisa Agropecuária Brasileira, v.41, p.1721-1730, 2006.

CAVALCANTI, L.S.; BRUNELLI, K.R.; STANGARLIN, J.R. Aspectos bioquímicos e moleculares da resistência induzida. In: CAVALCANTI, L.S.; DI PIERO, R.M.; CIA, P.; PASCHOLATI, I.S.F.; RESENDE, M.L.V.; ROMEIRO, R.S. (Ed.). Indução de resistência em plantas a patógenos e insetos. Piracicaba: FEALQ, 2005. p.81-124.
DANNER, M.A.; SASSO, S.A.Z.; MEDEIROS, J.G.S.; MARCHESE, J.A.; MAZARO, S.M. Indução de resistência à podridão-parda em pêssegos pelo uso de eliciadores em pós-colheita. Pesquisa Agropecuária Brasileira, v.43, p.793-799, 2008.

DI PIERO, R.M.; GARDA, M.V. Quitosana reduz a severidade da antracnose e aumenta a atividade de glucanase em feijoeiro-comum. Pesquisa Agropecuária Brasileira, v.43, p.1121-1128, 2008.

DUBOIS, M.; GILLES, K.A.; HAMILTON, J.K.; REBERS, P.A.; SMITH, F. Colorimetric method for determination of sugars and related substances. Analytical Biochemistry, v.28, p.350-356, 1956.

DURRANT, W.E.; DONG X. Systemic acquired resistance. Annual Review of Phytopathology, v.42, p.185-209, 2004.

EL GHAOUTH, A.; ARUL, J.; GRENIER, J.; BENHAMOU, N.; ASSELIN, A.; BÉLANGER, R. Effect of chitosan on cucumber plants: suppression of Pythium aphanidermatum and induction of defense reactions. Phytopathology, v.84, p.313-320, 1994.

HEIL, M.; BOSTOCK, M.R. Induced systemic resistance (ISR) against pathogens in the context of induced plant defences. Annals of Botany, v.89, p.503-512, 2002.

KUHN, O.J. Indução de resistência em feijoeiro (Phaseolus vulgaris) por acibenzolar-S-metil e Bacillus cereus: aspectos fisiológiocos, bioquímicos e parâmetros de crescimento e produção. 2007. 140p. Tese (Doutorado) - Escola Superior de Agricultura Luiz de Queiroz, Piracicaba.

LABANCA, E.R.G. Purificação parcial de elicitores presentes em Saccharomyces cerevisiae: atividade como indutores de resistência em pepino (Cucumis sativus) contra Colletotrichum lagenarium e da síntese de gliceolinas em soja (Glycine max). 2002. 107p. Dissertação (Mestrado) Escola Superior de Agricultura Luiz de Queiroz, Piracicaba.

LEMOS, S.D. da C. Avaliação de eliciadores do metabolismo dos fenilpropanóides em Melissa officinalis L. (Lamiaceae). 2006. 85p. Dissertação (Mestrado) - Pontifícia Universidade Católica do Rio Grande do Sul, Porto Alegre.

MATHUR, N.K.; NARANG, C.K. Chitin and chitosan, versatile polysaccharides from marine animals. Journal of Chemical Education, v.67, p.938-942, 1990.

MAZARO, S.M. Indução de resistência a doenças em morangueiro pelo uso de elicitores. 2007. 87p. Tese (Doutorado) - Universidade Federal do Paraná, Curitiba.

MAZARO, S.M.; CITADIN, I.; GOUVÊA, A. de; LUCKMANN, D.; GUIMARÃES, S.S. Indução de fitoalexinas em cotilédones de soja em resposta a derivados de folhas de pitangueira. Ciência Rural, v.38, p.1824-1829, 2008.

MILLER, G.L. Use of dinitrosalicylic and reagent for determination of reducing sugar. Analytical Chemistry, v.31, p.426-428, 1959.

PEREIRA, R.B.; RESENDE, M.L.V. de; RIBEIRO JÚNIOR, P.M.; AMARAL, D.R.; LUCAS, G.C.; CAVALCANTI, F.R. Ativação de defesa em cacaueiro contra a murcha-de-verticílio por extratos naturais e acibenzolar-S-metil. Pesquisa Agropecuária Brasileira, v.43, p.171-178, 2008. 
RODRIGUES, A.A.C.; NETO, E.B.; COELHO, R.S.B. Indução de resistência a Fusarium oxysporum f. sp. Tracheiphilum em caupi: eficiência de indutores abióticos e atividade enzimática elicitada. Fitopatologia Brasileira, v.31, p.492-499, 2006.

ROMANAZZI, G.; NIGRO, F.; IPPOLITO, A.; DI VENERE, D.; SALERNO, M. Effects of Pre- and postharvest chitosan treatments to control storage gray mold of Table grapes. Journal of Food Science, v.67, p.1862-1867, 2002.

SILVA, R.F. Indução de resistência em plantas de berinjela e tomate por Lentinula edodes e Agaricus blazei contra bactérias causadoras de murcha (Ralstonia solanacearum) e cancro (Clavibacter michiganensis subsp. michiganensis). 2007. 109p. Tese (Doutorado) - Escola Superior de Agricultura Luiz de Queiroz, Piracicaba.

TAIZ, L.; ZEIGER, E. Fisiologia vegetal. 3.ed. Porto Alegre: Artmed, 2004. 719p.
TERRY, L.A.; JOYCE, D.C. Elicitors of induced disease resistance in postharvest horticultural crops: a brief review. Postharvest Biology and Technology, v.32, p.1-13. 2004.

WORDELL FILHO, J.A.; MARTINS, D.A.; STADNIK, M.J. Aplicação foliar de tratamentos para o controle do míldio e da podridão-de-escamas de bulbos de cebola. Horticultura Brasileira, v. 25, p.544-549, 2007.

ZHANG, D.L.; QUANTICK, P.C. Antifungal effects of chitosan coating on fresh strawberries and raspberries during storage. Journal of Horticultural Science Biotechnology, v.73, p.763-767, 1998.

ZHANG, D.L.; QUANTICK, P.C. Effects of chitosan coating on enzymatic browning and decay during postharvest storage of litchi (Litchi sinensis Sonn.) fruit. Postharvest Biology and Technology, v.12, p.195-202, 1997.

ZONTA, E.P.; MACHADO A.A. Sistema de análise estatística para microcomputadores. Pelotas: UFPel, 1984. 150p.

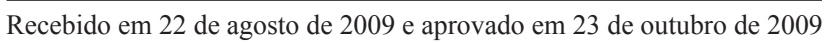

